\title{
A mathematical and testing tool for personal human capital research assessment
}

\author{
Galyna Malynovska ${ }^{a}$, Sviatoslav Kis ${ }^{b}$, Yaryna Kalambet ${ }^{\mathrm{c}}$ and Oleh Yatsiuk ${ }^{\mathrm{d}^{*}}$
}

${ }^{a}$ Department of Theory of Economics and Management, Post-Graduate Student, Ivano-Frankivsk National Technical University of Oil and Gas, Ivano-Frankivsk, Ukraine

${ }^{b}$ Department of Theory of Economics and Management, Professor, Doctor of Science in Economics, Ivano-Frankivsk National Technical University of Oil and Gas, Ivano-Frankivsk, Ukraine

${ }^{c}$ Department of Philology, Interpreting and Translation, PhD (Germanic Languages), Associate Professor, Ivano-Frankivsk National Technical University of Oil and Gas, Ivano-Frankivsk, Ukraine

${ }^{d}$ Department of Theory of Economics and Management, Assistant of Professor, Ivano-Frankivsk National Technical University of Oil and Gas, Ivano-Frankivsk, Ukraine

\section{H R O N I C L E}

\section{Article history:}

Received: May 29, 2020

Received in revised format:

May 302020

Accepted: June 3, 2020

Available online:

June 4, 2020

Keywords:

Human capital

Individual intelligence

Creative ability

Social ability

Status ability

\section{A B S T R A C T}

This article establishes and grounds the topicality of personal human capital for its development. It proves that the available approaches, methods and models do not consider the business enterprise needs to increase the efficiency of individual employee's contribution to the formation of market value. Human capital is offered to consider as a function of personal intelligence, which depends on the personal creative, status and social abilities. The adaptation of mathematical tools is conducted to establish intellectual personal characteristics with justification of different variants of their numerical values. The article also completes the evaluation tools by way of questionnaires, tests and personal objective characteristics, and suggests the approaches to the procedure of results evaluation and interpretation. The testing of the mathematical and testing tools of the personal human capital research was conducted with a group of people whose team is as close as possible to a typical industrial staff workers or its structural subdivision. The results of the personal human capital survey allowed us to identify both individual and collective needs in improving the planning processes for its development.

\section{Introduction}

The resource provision is the principal element for economic processes implementation, its quantitative and qualitative state considerably determines the business performance, regardless of its purpose and subject. With a particular focus on the diversity of approaches to the economic resource classification, the most used in economic science and practice is concluded an approach that provides their division into material and immaterial parts. If aspects that are related to the involvement and use of material component of the economic process get specific results for their solution in both theoretical and practical terms, then immaterial resources often become prone to scientific debate, and their role for business performance and outcomes are poorly understood by business entities. Under current conditions the lack of natural, material, information, financial and other resources arise quite sharply, so their solution needs new and modern ideas. One of the most effective compensators for a resource deficit is recognized to be a human capital resource, which is changed to potential and used as a part of business capital. Herewith, another scientific problem arises, which aims the necessity to research the human capital (HC) in order to find and justify the ways of its effective involvement in business activity. The development (improvement) and further testing of the evaluation tools shall be considered as the main practical task because it will enable the business managers to make decisions based on relevant information about the HC. Such an approach gives an option of more effective implementation

* Corresponding author. Tel.: +380504331763

E-mail address: olegstya@gmail.com (O. Yatsiuk) 
for the $\mathrm{HC}$ development and, as a consequence, optimizes the use of investment (financial) resources for these purposes.

\section{Literature Review and Hypothesis Development}

The problems of subject, structure and many other theoretical and methodological aspects related to the economic category of "human capital" are widely represented in domestic and foreign scientific literature (Grishnova \& Tertichna, 2003; Chukhno, 2002; Ushenko, 2008; Petrenko \& Matskevich, 2014, Brintseva, 2016, Becker, 1964, Edvinsson \& Malone, 1997; Patrick, 2000). Most of them have already got the considerable and well-founded conclusions, the started before researches are being improved with new theoretical approaches and models, while others still remain the subject to scientific discussions. The HC research represents the development and improvement of many approaches concerning the issues of its participation in economic processes. In particular, a significant number of scientific publications have been devoted to the HC evaluation, the primary purpose of which, to our mind, is the quantitative or qualitative model of the management object. Domestic and foreign scientists draw the most attention to the evaluation of, first, expenses on HC forming or real expenses on human living, and secondly, modified to the valuation point of future income value earned by a person (Ushenko, 2008). Herein, the authors use such objective indices as educational costs, advanced training and informal education investments, employment wages, income and others (Grishnova \& Tertichna, 2003; Chukhno, 2002). This work presents a generalized characteristic of the basic evaluation methods for the $\mathrm{HC}$ at the state level, including on the ground of some economic ratings (Pishchulin et al., 2018). In our opinion, in a macroeconomic manner, the most prevailing within ranking is the methodology, which is used by the World Economic Forum in The Global Human Capital Report (2017) to make a report for the current year, and includes indices in the following areas - education, public health service and wealth, labor and employment, environmental favorableness. Thus, if issues for $\mathrm{HC}$ evaluation do not involve to scientific debate nationwide, then the microeconomic aspects of this issue, despite their popularity as an object of theoretical and methodological research, require enhanced approaches, techniques and models that, being scientifically proven and well-founded, perform an important practical function in the processes of business activity of microeconomic entities.

The first-priority aspect within enterprise HC performance is the identification and recognition of the end goal, which, in one respect, may be aimed at establishing or fixing the $\mathrm{HC}$ value of the business entity for its market positioning (market capitalization), and in the other - to determine the personal HC state, to control the processes of its development. On practical grounds, the second position possesses higher value, it appreciates the necessity to consider the potential contribution of every employee in making the market value of the business entity.

\section{Methodology}

With a variety of scientific approaches for the collective and individual $\mathrm{HC}$ evaluation, we draw our attention to a calculation formula given in (Horovy, 2014), which provides for the employee performance potential by getting wages on the goodwill of his human capacity or resources. In that event, the goodwill of human capacity is calculated for each employee individually and considers the individual employee value as a specific person who is able to perform certain functions, solve certain tasks, but the parameters for goodwill calculations are not clearly established. Thus, it is right to state that a personal goodwill may be considered as an immaterial asset, determined by human intelligence or individual intelligence, and the calculation HC formula acquires the form of the product of the set value of the objective cost characteristics of the person (wages, expenses, income, etc.) on the coefficient of the individual $\left(K_{I I}\right)$. In connection with this, it appears a task related to identification of parameters and calculation methods $K_{I I}$. The (Kis et al., 2019) attempts to solve the set task, where the authors suggest a characteristics matrix (model) of the HC common carrier as a tool to manage the processes of its planning, formation, development and efficiency of enterprise HC. Substantiating the individual's HC dependence on his/her individual intelligence ( $H C=F(I I)$ ), the scientists suggest identify and position II individuals on the following three characteristics: creative ability, status ability and social ability, each of which, in its turn, is differentiated by three corresponding criteria. Thus, a 3D matrix of the personal intellectual characteristics has been made in the coordinates "creative ability - social ability - status ability", which, for its further practical use, requires the selection, substantiation and approbation of mathematical and testing tools for performing the functions of personal $\mathrm{HC}$ research. If $H C=F(I I)$, then II is an independent variable that fully defines the $\mathrm{HC}$ and depends on three abilities of each individual: creative ability $(\operatorname{Cr} A)$, social ability ( $S c A)$, and status ability $(S t A)$. Thus, $I I=u(C r A, S c A, S t A)$, where $u$ is an unknown function of three variables that increases with the grows of each of them. In this case, the mathematical problem is aimed to find a function that meets these conditions and to calibrate the individual intelligence.

Under the aims and goals of this research and taking into account the results of previous scientific works (Kis et al., 2019), we formulate the following assumptions:

$\operatorname{Cr} A \in\left[0 ; \max _{C r A}\right]$, where $\max _{C r A}$ - the maximum possible value of personal creative ability;

$S c A \in\left[0 ; \max _{S c A}\right]$, where $\max _{S c A}$ - the maximum possible value of personal social ability;

$S t A \in\left[0 ; \max _{S t A}\right]$, where $\max _{S t A}$ - the maximum possible value of personal status ability. 
Similarly to the graphical approach given in (Kis et al., 2019), the interval of change of each ability type is divided into three subintervals, which characterize different states for $\operatorname{Cr} A, S c A, S t A$. In particular, the $S c A$ parameter can be in such three states:

selfish intelligence $(E g I)$ under $S c A \in\left[0 ; \max _{S c A} / 3\right]$;

rational intelligence $(E g I-A I)$ under $S c A \in\left[\max _{S c A} / 3 ; 2 \cdot \max _{S c A} / 3\right]$;

altruistic intelligence $(A I)$ under $S c A \in\left[2 \cdot \max _{S c A} / 3 ; \max _{S c A}\right]$.

The $\operatorname{Cr} A$ parameter can be in such three states:

ordinary intelligence $(O I)$ under $\operatorname{Cr} A \in\left[0 ; \max _{C r A} / 3\right]$;

extraordinary intelligence $(N I)$ under $C r A \in\left[\max _{C r A} / 3 ; 2 \cdot \max _{C r A} / 3\right]$;

elite intelligence $(E I)$ under $\operatorname{Cr} A \in\left[2 \cdot \max _{C r A} / 3 ; \max _{C r A}\right]$.

The given belows parameters are for $S t A$ :

executive intelligence $(I P)$ under $S t A \in\left[0 ; \max _{C r A} / 3\right]$;

intelligence manager менеджера $(I M)$ under $S t A \in\left[\max _{S t A} / 3 ; 2 \cdot \max _{S t A} / 3\right]$;

leadership intelligence $(I L)$ under $S t A \in\left[2 \cdot \max _{S t A} / 3 ; \max _{S t A}\right]$.

The simplest variant of an unknown function $u$ can be a Euclidean (natural) norm in three-dimensional real space, that is,

$$
u=\|\cdot\|_{\mathrm{R}^{3}} \text {. }
$$

It is to be recalled that the Euclidean norm in the mentioned space for the $(x, y, z) \in \mathrm{R}^{3}$ vector is defined as the modulus of this vector, i.e. its length (absolute value):

$$
\|(x, y, z)\|=\sqrt{x^{2}+y^{2}+z^{2}} .
$$

Hence, with this $u$ function selection, the normalized measure of individual intelligence can be calculated as follows:

$$
I I=\sqrt{\frac{C r A^{2}+S c A^{2}+S t A^{2}}{3}}
$$

Besides, a unit vector for personal intellectual characteristic can also describe II, and which is defined as an orth from a vector of three coordinates $\operatorname{Cr} A, S c A, S t A$ :

$$
\mathrm{IX}=\frac{1}{\mathrm{II}} \cdot\left(\frac{C r A}{\sqrt{3}}, \frac{S c A}{\sqrt{3}}, \frac{S t A}{\sqrt{3}}\right)=\left(\frac{C r A}{\sqrt{\frac{C r A^{2}+S c A^{2}+S t A^{2}}{3}}}, \frac{S c A}{\sqrt{\frac{C r A^{2}+S c A^{2}+S t A^{2}}{3}}}, \frac{S t A}{\sqrt{\frac{C r A^{2}+S c A^{2}+S t A^{2}}{3}}}\right)
$$

The perfect variant of unit vector for personal intellectual characteristic looks as follows:

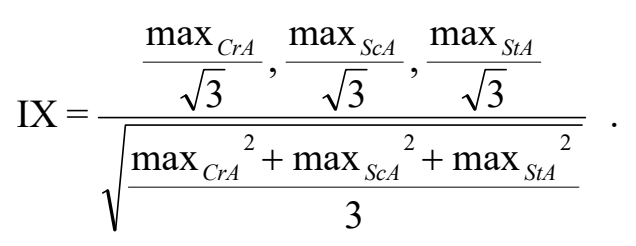

Apart from the perfect variant, one can alaso define both the vector of unbalance of personal intellectual characteristic $(\overrightarrow{u r})$ in Eq. (6), and the corresponding index ( $u r$ ) in Eq. (7):

$$
\overrightarrow{u r}=\frac{\left(\max _{C r A}-C r A ; \max _{S c A}-S c A ; \max _{S t A}-S t A\right)}{\sqrt{3}} .
$$




$$
u r=\max \frac{\left\{\max _{C r A}-C r A ; \max { }_{S c A}-S c A ; \max { }_{S t A}-S t A\right\}}{\sqrt{3}} .
$$

Taking into consideration that it is likely possible to develop a perfect variant of unit vector for personal intellectual characteristic, we believe that a sufficient condition for the indices $\operatorname{Cr} A, S c A, S t A$ is compliance with two-thirds of their maximum value $\left(\mathrm{v} \frac{2}{3} \cdot \max _{C r A} ; \frac{2}{3} \cdot \max _{S c A} ; \frac{2}{3} \cdot \max _{S t A}\right)$. In such a circumstance, the so-called corrected unbalance vector $\rightarrow$

( $c u r$ ) is advised to consider:

$$
\overrightarrow{c u r}=\frac{\left(\operatorname{Cr} A-\frac{2}{3} \cdot \max _{C r A} ; S c A-\frac{2}{3} \cdot \max _{S c A} ; S t A-\frac{2}{3} \cdot \max _{S t A}\right)}{\sqrt{3}} .
$$

If all its components are positive, then the person can be considered as one who meets the perfect variant. If even one component is negative, the related ability needs to be improved or must be taken into account when deciding on its further development. The next stage in the personal human capital research shall be the search, justification and adaptation of evaluation tools represented by questionnaires, tests and objective personal characteristics. Referring a personal creativity with his/her readiness or availability for creative analysis and information synthesis, industrial processes organization and implementation, own and borrowed ideas generation and implementation which are identified in (Kis, 2016) as a process of intellectualization, we advise to evaluate $\operatorname{Cr} A$ by using the author's questionnaire. The questionnaire form consists of 33 questions with the given response format: agree -3 scores, disagree -1 score, hesitate -0 scores. The results of the survey are determined in three question pools, each of them settles the sum of points. The question pool, where the respondent gets the highest number of scores, affords to further level identification of creative ability at such numerical intervals: from 0 to 0,399- low, from 0,4 to 0,699-medium, from 0,7 to 1 - high. Hence, the personal survey results look as follows (Table 1 ):

Table 1

The interpretation of survey scores for a personal $\mathrm{Cr} A$ determination

\begin{tabular}{ccccc}
\hline $\begin{array}{c}\text { Question № } \\
\text { in a questionnaire form }\end{array}$ & $\begin{array}{c}\text { Leve of creative } \\
\text { ability } \\
\left(C r A_{\text {level }}\right)\end{array}$ & $\begin{array}{c}\text { Maximum score } \\
\left(\max _{\text {scores }}\right)\end{array}$ & $\begin{array}{c}\text { Gained score } \\
\left(\sum \text { scores }\right)\end{array}$ & $\begin{array}{c}\text { Creativity weighting ratio } \\
\text { scores } \\
\left(K_{C r A}=\frac{\sum^{2}}{33}\right.\end{array}$ \\
\hline $1,2,4,15,17,22,23,24,26,27,28$ & high & 33 & $\mathrm{X}$ & $\mathrm{X}$ \\
$3,8,10,11,12,16,29,30,31,32,33$ & medium & 33 & $\mathrm{X}$ & $\mathrm{X}$ \\
$5,6,7,9,13,14,18,19,20,21,25$ & low & 33 & $\mathrm{X}$ & $\mathrm{X}$ \\
\hline
\end{tabular}

The level of personal creativity capacity correction is suggested to do as follows:

$$
\operatorname{Cr} A_{\text {level }}=\max _{C r A_{\text {level }}} \times K_{C r A} \text {, }
$$

where $\max _{C r A_{\text {level }}}$ is the maximum value of creativity that can gain a value of $0.399,0.699$, or 1 at each level. To identify the personal values $S c A$ we suggest that social ability is considered as the recognition and consideration of others' opinion (above all, staff members or department and business members), ability to handle in conflict situations, make decisions oriented on preliminary consultations, and other. From this perspective, $S c A$ diagnostics is most appropriate to conduct by using a well-known Kenneth Thomas and Ralph Kilmann's survey, the content and the ability of test completing are available on many online resources.

Adjusting in accordance with the method of Thomas-Kilmann to the need to determine the numerical value $S c A$, we result in making a similar to the Table 1 form of diagnostic results establishing (Table 2):

Thus,

$$
S c A_{\text {level }}=\max _{S c A_{\text {level }}} \times K_{S c A},
$$

where, $\max _{S c A_{\text {level }}}$ is the maximum value of creativity that can gain a value of $0.399,0.699$, or 1 at each level. Status ability (status social ability, potential social status or rank) is one of the most important personal characteristics. Nobel Laureate economist, John Harsanyi, said that "Apart from economic payoffs, social status (social rank) seems to be the most important incentive and motivating force of social behavior" (Harsanyi, 1980). 
Table 2

The interpretation of survey scores for a personal $S c A$ determination

\begin{tabular}{|c|c|c|c|c|}
\hline $\begin{array}{c}\text { Question № } \\
\text { in a Ralph Kilmann’s survey }\end{array}$ & $\begin{array}{c}\text { Level of social } \\
\text { ability } \\
\left(S c A_{\text {level }}\right)\end{array}$ & $\begin{array}{l}\text { Maximum score } \\
\left(\max _{\text {scores }}\right)\end{array}$ & $\begin{array}{l}\text { Gained score } \\
\left(\sum \text { scores }\right)\end{array}$ & $\begin{array}{l}\text { Social ability weighting ratio } \\
\qquad\left(K_{S c A}=\frac{\sum \text { scores }}{\max _{\text {scores }}}\right)\end{array}$ \\
\hline $\begin{array}{l}3 \mathrm{~A}, 6 \mathrm{~B}, 8 \mathrm{~A}, 9 \mathrm{~B}, 10 \mathrm{~A}, 13 \mathrm{~B}, 14 \mathrm{~B}, 16 \mathrm{~B}, 17 \mathrm{~A}, 22 \mathrm{~B} \\
25 \mathrm{~A}, 28 \mathrm{~A}, 1 \mathrm{~A}, 5 \mathrm{~B}, 6 \mathrm{~A}, 7 \mathrm{~A}, 9 \mathrm{~A}, 12 \mathrm{~A}, 15 \mathrm{~B}, 17 \mathrm{~B}, 19 \mathrm{~B} \\
20 \mathrm{~B}, 27 \mathrm{~A}, 29 \mathrm{~B}\end{array}$ & low & 24 & $\sqrt{ }$ & $\sqrt{ }$ \\
\hline $\begin{array}{l}2 \mathrm{~B}, 5 \mathrm{~A}, 8 \mathrm{~B}, 11 \mathrm{~A}, 14 \mathrm{~A}, 19 \mathrm{~A}, 20 \mathrm{~A}, 21 \mathrm{~B}, 23 \mathrm{~B}, 26 \mathrm{~B} \\
28 \mathrm{~B}, 30 \mathrm{~B}, 1 \mathrm{~B}, 3 \mathrm{~B}, 4 \mathrm{~B}, 11 \mathrm{~B}, 15 \mathrm{~A}, 16 \mathrm{~A}, 18 \mathrm{~A}, 21 \mathrm{~A} \\
24 \mathrm{~A}, 25,27 \mathrm{~B}, 30 \mathrm{~A}\end{array}$ & medium & 24 & $\sqrt{ }$ & $\sqrt{ }$ \\
\hline $\begin{array}{l}2 \mathrm{~A}, 4 \mathrm{~A}, 7 \mathrm{~B}, 10 \mathrm{~B}, 12 \mathrm{~B}, 13 \mathrm{~A}, 18 \mathrm{~B}, 22 \mathrm{~A}, 23 \mathrm{~A}, 24,26 \mathrm{~A} \text {, } \\
29 \mathrm{~A} \text {. }\end{array}$ & high & 12 & $\sqrt{ }$ & $\sqrt{ }$ \\
\hline
\end{tabular}

Concerning the StA parameters (its constituents), among a great number of opinions on this issue (Ridgeway, 2014; Ridgeway, 2011; Fiske, 2011; Fiske at al., 2002) it is possible to determine those that are shared by the most scientific researches and are suitable for evaluation of staff members: position, education, knowledge, skills, professional behavior and competence, income.

The evaluation of the selected subjective and objective parameters $S t A$ is suggested to perform by the given below algorithm:

1) $\quad \mathrm{StA}$ personal parameters estimation;

2) personal $S t A$ determination;

3) interpretation of survey scores for a personal $S t A$.

Table 3 presents the evaluation (self-evaluation) for a personal $S t A$ due to the mentioned above components of status ability. The expert method determines a weighting ratio $k_{i}$ in such a way that equality is satisfied:

$$
\sum_{i=1}^{6} \kappa_{i}=1
$$

Generally, personal $S t A$ is determined by the following formula:

$$
S t A=\sum_{i=1}^{6} \kappa_{i} \frac{t_{i}}{t_{\max i}}
$$

Interpretation of results score for a personal $S t A$ determination:

$0 \leq S t A \leq 0,399$ - low-level of status ability;

$0,4 \leq S t A \leq 0,699$ - middle-level of status ability;

$0,7 \leq$ StA $\leq 1-$ high-level of status ability.

\section{Results}

Testing is an important stage in the personal human capital research due to the above approach. It will allow verify the developed and adapted tools in real conditions. In this regard, we made a decision to conduct a survey of a group of 20 people who, as of 01/11/2019, were awarded a Master's degree (second cycle of higher education) at the Institute of Postgraduate Education (IPO) of the Ivano-Frankivsk National Technical University of Oil and Gas (IFNTUNG) in oil and gas majors. The defined respondents are employees of one of the largest oils and gas company in Ukraine, which includes geographically remote production departments. Following the results of the preparation for the human capital research procedures, it was found out that persons who agreed to take the survey possess both common and distinctive objective characteristics, which makes it possible to conclude on representative sample and it is as close as possible to the typical staff members or department and business members.

The survey primarily was conducted using interview technology, in which the respondent was asked to complete Table 3 and calculate the total score by himself/herself. To obtain the calculation information on $\mathrm{Cr} A$ and $S c A$, we created an appropriate google form, made it available to all respondents, and calculated the results automatically. By means of the obtained data, we formed a summarized table indicating the survey results, testing and mathematical calculations using the above method (Table 4). We used the Microsoft Excel to process the input data while summarizing the results. 
Table 3

StA personal parameters estimation

\begin{tabular}{|c|c|c|c|c|c|c|}
\hline Parameter & 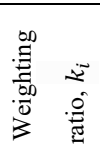 & 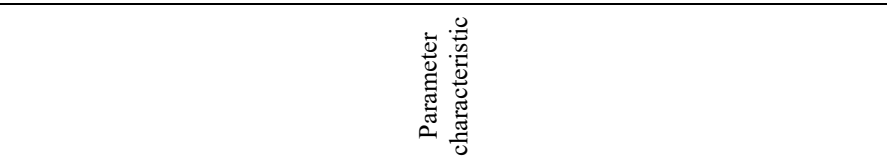 & 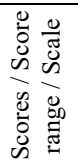 & 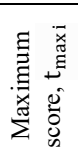 & 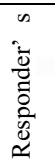 & \\
\hline \multirow{3}{*}{ Position } & \multirow{3}{*}{0,2} & Low-level manager & 1 & \multirow{3}{*}{3} & & \\
\hline & & Middle-level manager & 2 & & & \\
\hline & & Top-level manager & 3 & & & \\
\hline \multirow{6}{*}{ Education } & \multirow{6}{*}{0,15} & Informal education (courses, training, seminars etc.) & 1 & \multirow{6}{*}{20} & & \\
\hline & & Bachelor's degree & 2 & & & \\
\hline & & Specialist's degree & 3 & & & \\
\hline & & Master's degree & 4 & & & \\
\hline & & Master of Business Administration & 5 & & & \\
\hline & & PhD degree & 5 & & & \\
\hline \multirow[b]{2}{*}{ Knowledge } & \multirow[b]{2}{*}{0,17} & Required level of knowledge for professional duties on a current position & $1-10$ & \multirow[b]{2}{*}{20} & & \\
\hline & & $\begin{array}{l}\text { Required level of knowledge for professional duties on a higher position, run by a } \\
\text { person }\end{array}$ & $1-10$ & & & \\
\hline \multirow{2}{*}{ Skills } & \multirow{2}{*}{0,18} & Required level of skills for professional duties on a current position & $1-10$ & \multirow{2}{*}{20} & & \\
\hline & & Required level of skills for professional duties on a higher position, run by a person & $1-10$ & & & \\
\hline \multirow{2}{*}{ Professional behavior } & \multirow{2}{*}{0,18} & $\begin{array}{l}\text { Required level of professional behavior for professional duties on a current posi- } \\
\text { tion }\end{array}$ & $1-10$ & \multirow[t]{2}{*}{20} & & \\
\hline & & $\begin{array}{l}\text { Required level of professional behaviour for professional duties on a higher posi- } \\
\text { tion, run by a person }\end{array}$ & $1-10$ & & & \\
\hline \multirow{3}{*}{ Income } & \multirow{3}{*}{0,12} & Low income & 1 & \multirow{3}{*}{3} & & \\
\hline & & Middle income & 2 & & & \\
\hline & & High income & 3 & & & \\
\hline Total & $\sqrt{ }$ & & $\sqrt{1}$ & 86 & $\sqrt{ }$ & \\
\hline
\end{tabular}

\section{Discussion}

The obtained results analysis of a personal human capital research among the employees of the oil and gas enterprise, with the above mentioned numerical intervals of the values $\mathrm{CrA}, \mathrm{ScA}, \mathrm{St} A$ allows us to conclude on the following:

1. The highest average value was set according to the personal intelligence parameter as $S c A(0.66)$, and the lowest $-\operatorname{Cr} A$ (0.59).

2. Generally talking, a group of people is characterized by the following characteristics $\mathrm{CrA}, \mathrm{ScA}, \mathrm{StA}$ :

by $C r A$ parameter: 0,74 - maximum value; 0,46- minimum value; $75 \%$ respondents show a middle level of $C r A, 25 \%-$ high one;

0,31 - maximum unbalance value; 0,15 - minimum unbalance value;

by $S c A$ parameter: 0,77 - maximum value; 0,48 - minimum value; $60 \%$ respondents show a middle level of $S c A, 40 \%-$ high one; 0,30 - maximum unbalance value; 0,11 - minimum unbalance value;

by StA parameter: 0,73 - maximum value; 0,48 - minimum value; $80 \%$ respondents show a middle level of $S c A, 20 \%-$ high one; 0,30 - maximum unbalance value; 0,16 - minimum unbalance value.

Table 4

Results on personal human capital research

\begin{tabular}{|c|c|c|c|c|c|c|c|c|c|c|}
\hline $\begin{array}{c}\text { Respondent }\left(R_{j}\right) \text {. where } j-\text { Respondent's } \\
\text { number }\end{array}$ & $\operatorname{Cr} A$ & $S c A$ & $S t A$ & $I I$ & & $\overrightarrow{u r}$ & & & $\overrightarrow{c u r}$ & \\
\hline$R_{I}$ & 0.46 & 0.65 & 0.58 & 0.57 & 0.31 & 0.20 & 0.24 & -0.12 & -0.01 & -0.05 \\
\hline$R_{2}$ & 0.49 & 0.62 & 0.61 & 0.58 & 0.29 & 0.22 & 0.22 & -0.10 & -0.03 & -0.03 \\
\hline$R_{3}$ & 0.71 & 0.51 & 0.63 & 0.62 & 0.17 & 0.28 & 0.21 & 0.02 & -0.09 & -0.02 \\
\hline$R_{4}$ & 0.53 & 0.49 & 0.57 & 0.53 & 0.27 & 0.29 & 0.25 & -0.08 & -0.10 & -0.05 \\
\hline$R_{5}$ & 0.65 & 0.67 & 0.55 & 0.62 & 0.20 & 0.19 & 0.26 & -0.01 & 0.01 & -0.07 \\
\hline$R_{6}$ & 0.58 & 0.71 & 0.48 & 0.60 & 0.24 & 0.17 & 0.30 & -0.05 & 0.02 & -0.11 \\
\hline$R_{7}$ & 0.54 & 0.75 & 0.71 & 0.67 & 0.26 & 0.14 & 0.17 & -0.07 & 0.05 & 0.02 \\
\hline$R_{8}$ & 0.48 & 0.77 & 0.69 & 0.66 & 0.30 & 0.13 & 0.18 & -0.11 & 0.06 & 0.01 \\
\hline$R_{9}$ & 0.73 & 0.69 & 0.63 & 0.68 & 0.15 & 0.18 & 0.21 & 0.04 & 0.01 & -0.02 \\
\hline$R_{10}$ & 0.71 & 0.68 & 0.62 & 0.67 & 0.17 & 0.19 & 0.22 & 0.02 & 0.01 & -0.03 \\
\hline$R_{11}$ & 0.47 & 0.7 & 0.71 & 0.64 & 0.30 & 0.18 & 0.17 & -0.11 & 0.02 & 0.02 \\
\hline$R_{12}$ & 0.53 & 0.75 & 0.62 & 0.64 & 0.27 & 0.15 & 0.22 & -0.08 & 0.05 & -0.03 \\
\hline$R_{13}$ & 0.59 & 0.65 & 0.7 & 0.65 & 0.24 & 0.21 & 0.17 & -0.04 & -0.01 & 0.02 \\
\hline$R_{14}$ & 0.65 & 0.65 & 0.73 & 0.68 & 0.20 & 0.21 & 0.15 & -0.01 & -0.01 & 0.04 \\
\hline$R_{15}$ & 0.55 & 0.58 & 0.62 & 0.58 & 0.25 & 0.24 & 0.22 & -0.07 & -0.05 & -0.03 \\
\hline$R_{16}$ & 0.66 & 0.77 & 0.52 & 0.66 & 0.20 & 0.13 & 0.28 & -0.01 & 0.05 & -0.08 \\
\hline$R_{17}$ & 0.48 & 0.8 & 0.58 & 0.63 & 0.30 & 0.11 & 0.24 & -0.10 & 0.08 & -0.05 \\
\hline$R_{18}$ & 0.52 & 0.48 & 0.62 & 0.54 & 0.28 & 0.30 & 0.22 & -0.08 & -0.11 & -0.03 \\
\hline$R_{19}$ & 0.71 & 0.65 & 0.48 & 0.62 & 0.17 & 0.20 & 0.30 & 0.02 & -0.01 & -0.11 \\
\hline
\end{tabular}




\begin{tabular}{ccccccccccc}
\hline$R_{20}$ & 0.74 & 0.7 & 0.59 & 0.68 & 0.15 & 0.17 & 0.24 & 0.04 & 0.02 & -0.04 \\
\hline \multicolumn{6}{c}{$\rightarrow$} & & &
\end{tabular}

3. Through the results of coordinate values cur analysis, it is established:

$25 \%$ of respondents show corrected unbalance in three coordinates, $45 \%$ - in two coordinates, $30 \%$ - in one coordinate;

$75 \%$ of respondents need adjusting of $\operatorname{Cr} A, \%-S c A, 75 \%-S t A$;

The lowest value of $\overrightarrow{c u r}$ is $-0,12$ by $\operatorname{Cr} A$ parameter, $-0,11$ by $\operatorname{Sc} A$ and $S t A$ parameters.

\section{Conclusion}

Thus, the suggested approach to the HC state determination, firstly, allows the HR Department to identify the individual needs and requirements for personal improvement by the defined parameters, to develop and implement personalized programs of its development. In particular, the evaluation results of the experimental employee group from the oil and gas company establish that the greatest influence on the improvement require such parameters as creativity and status abilities. In addition, information that enables the formation of three employee groups based on the criterion for the negative values of the coordinates of the vector of corrected imbalance is important for the effective organization of personnel management processes.

Based on the results of the research conducted, we believe that the developed mathematical and testing tools can be practically used as one of the elements of the enterprise $\mathrm{HC}$ evaluation methodology. In order to expand and improve its use, further scientific researches should be forwarded, first, to the search, development and adaptation of additional testing tools, as well as the continuation of mathematical processing and graphical interpretation of the results obtained by using probability theory and 3D modeling technology; secondly, to justify recommendations on mechanisms, models, trajectories generation approaches of individual development for business personnel.

\section{References}

Becker, G. S. (1964). Human Capital. New York: Columbia University Press.

Brintseva, O. (2016). Transformation of human capital in the context of changing the content of labor in the new economy. Ukraine: Aspects of Labour, 5-6, 3-9.

Chukhno, A. A. (2002). Intellectual capital: essence, forms and patterns of development. Ukraine economy, 11, 48-55.

Edvinsson, L., \& Malone, M. (1997). Intellectual Capital: Realizing Your Company's True Value by Finding Its Hidden Brainpower. New York: Harper Business.

Fiske, S. T. (2011). Envy Up, Scorn Down: How Status Divides Us. New York: Russell Sage Foundation.

Fiske, S. T., Cuddy, A. J., Glick, P., \& Jun Xu. (2002). A Model of (Often Mixed) Stereotype Content: Competence and Warmth Respectively Follow From Perceived Status and Competition. Journal of Personality and Social Psychology, 82, 878-902.

Grishnova, O., \& Tertichna, L. (2003). Economic nature and significance of the human capital category. Ukraine: aspects of work, 7, 33-37.

Harsanyi, J. C. (1980). A Bargaining Model for Social Status in Informal Groups and Formal Organizations. in: Harsanyi, J. C., Essays on Ethics, Social Behavior, and Scientific Explanation. Theory and Decision Library (An International Series in the Philosophy and Methodology of the Social and Behavioral Sciences), vol. 12, Springer, Dordrecht, pp. 204-224.

Horovy, D. A. (2014). Formation and assessment of human capital of a modern enterprise. Problems and prospects of entrepreneurship development. Collection of scientific works, 2, 186-191.

Kis, S., Malynovska, G., Petrenko V., \& Yatsiuk, O. (2019). Matrix of Personality Intelligent Characteristics as an Instrument for its Development Management. Proceedings of the 6th International Conference on Strategies, Models and Technologies of Economic Systems Management (SMTESM 2019), in series: Advances in Economics, Business and Management Research, Vol. 95, (October 4-6, 2019), Khmelnytskyi, Ukraine. Retrieved from https://www.atlantis-press.com/proceedings/smtesm-19/125917672.

Kis, S. Ya. (2016). Scientific bases of intellectualization of enterprise activity: dissertation. Ivano-Frankivsk: IvanoFrankivsk National Technical University of Oil and Gas.

Petrenko, V. P., \& Matskevich, O. Yu. (2014). Classification of human capital of the enterprise as a prerequisite for its productive use. Scientific Bulletin of the Kherson State University. Series: Economic Sciences, 5(2), 234-238.

Patrick, H. S. (2000). Value-driven Intellectual Capital: How to convert Intangible Corporate Assets into Market Value. Retrieved from http://www.sveiby.com/articles/icmmovement.htm

Pishchulin, O., Yurochko T., Mishchenko M., \& Zhalilo Y. (2018). Human Capital Development: Towards Quality Reforms. Kyiv: Testament.

Ridgeway, C. (2014). Why status matters for inequality. American Sociological Review, 79, 1-16.

Ridgeway, C. L. (2011). Framed by Gender: How Gender Inequality Persists in the Modern World. New York: Oxford University Press. 
The Global Human Capital Report 2017. Geneva: World Economic Forum. Retrieved from https://www.insidehighered.com/sites/default/server_files/files/WEF_Global_Human_Capital_Report_2017.pdf.

Ushenko, N. V. (2008). Human capital: formation in the system of education and vocational training. Donetsk: LLC "Southeast".

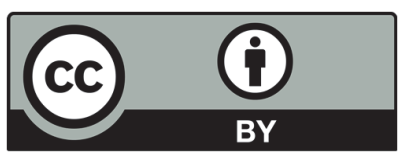

(C) 2020 by the authors; licensee Growing Science, Canada. This is an open access article distributed under the terms and conditions of the Creative Commons Attribution (CC-BY) license (http://creativecommons.org/licenses/by/4.0/). 